\title{
Squamous Cell Carcinoma of the Endometrium with Human Papillomavirus Type 31
}

\author{
AKIO KATAOKA, TAKASHI NISHIDA, HIDETO OKINA, YOSHITO TOMIOKA, \\ NOBUYUKI HIRAI, TORU SUGIYAMA AND MICHIAKI YAKUSHIJI \\ Department of Obstetrics and Gynecology, Kurume University School of Medicine, \\ Kurume 830, Japan
}

Received for publication November 21, 1996

\begin{abstract}
Key words uterine cancer, endometrial cancer, suamous cell carcinoma, HPV, PCR
\end{abstract}

Primary squamous cell carcinoma of the endometrium (ESCC) is an extremely rare entity. Moreover, there is no previous report of HPV in cases of ESCC (Fluhmann, 1928; Im et al. 1995; Yamamoto et al. 1995; Goodman et al. 1996).

A 64-year-old Japanese female underwent total abdominal hysterectomy, bilateral salpingo-oophorectomy, and removal of the pelvic, para-aortic, and bilateral inguinal lymph nodes. The tumor was confined to the endometrium, without invasion of the myometrium and cervix. The endometrium was replaced by a moderately differentiated squamous cell carcinoma without any adenocarcinoma element (Fig. 1A). The polymerase chain reaction (PCR) produces a 244-bp to 256-bp DNA fragment from the L1 region of the HPV genome (Yoshikawa et al. 1991). The amplification products were restricted, and the polymorphism patterns of the restricted fragmentation length were analyzed (Fig. 1B). The tumor showed presence of HPV
DNA. This amplified fragment was further purified by extraction with the agarose gel and the DNA was sequenced. Comparison of the fragment DNA sequence with the known PV sequences determined that the fragment was amplified from HPV type 31 (Yoshikawa et al. 1991).

If ESCC is to meet Fluhmann's strict criteria, it must be distinguished from invasion or surface spread of cervical squamous cell carcinoma (Fluhmann, 1928). Careful examination of the entire tumor must be performed to rule out endometrial carcinoma with squamous differentiation. Furthermore, the entire cervix must be sectioned to exclude the presence of squamous cell carcinoma. Goodman et al. (1996) reviewed the past reported 64 cases with their own eight cases, which fully satisfy Fluhmann's criterias. The findings in our case also fully satisfy Fluhman's criteria.

Since the reported cases of ESCC are few, the histogenesis and etiology of this tumor still remain unknown. The rela-

Address for correspondence: Akio Kataoka, MD, 67 Asahi-machi, Kurume 830, Japan.

Tel: 81-942-35-3311, Fax: 81-942-35-0238 

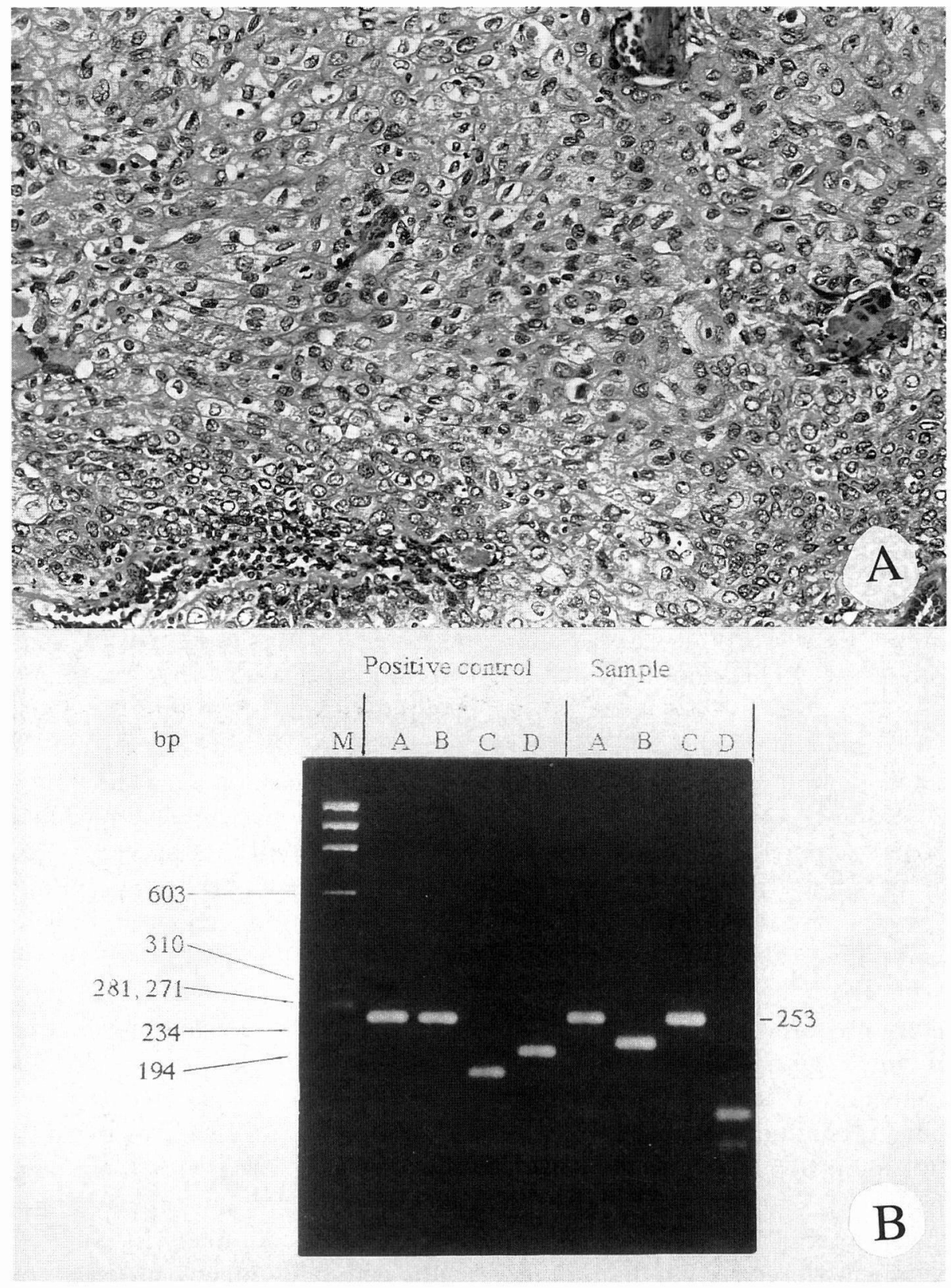

Fig. 1A. The tumor was a moderately differentiated squamous cell carcinoma with partial keratinization. $(\mathrm{H} . \& \mathrm{E}, \times 100)$

Fig. 1B. Restriction mapping of the L1-PCR product. Nine cloned HPV types were subjected L1-PCR. About 1/10th of the product was digested with the following restriction enzymes. Lane A, uncut; lane B, Rsa I; lane C, Dde I; lane D, Hae III. After electrophoresis, the gels were stained and photographed. Lane M is molecular marker $(\phi \times 174$ digested with Hae III). The presented pattern was only compatible with HPV type 31 (Yoshikawa et al. 1991). 
tionship between squamous metaplasia of the endometrium and ESCC remains controversial. Squamous metaplasia has been considered by some investigators as a precancerous stage of ESCC, based on observations of its coexistence with ESCC (Yamamoto et al. 1995; Czerwenka et al. 1996). However, according to Im et al. (1995) there is no convincing evidence to suggest that endometrial squamous metaplasia is the precursor of ESCC other than the coexistence of the two lesions seen in only 11 of 34 cases. Our case did not have squamous metaplasia, either.

A common cancer affecting women world-wide is the carcinoma of the uterine cervix. Infection with certain high-risk oncogenic genital HPV types have been closely associated with the initiation and development of cervical carcinoma (zur Hausen and de Villers, 1994). The first report of HPV status of ESCC by Im et al. (1995) revealed that all three cases failed to show presence of HPV, and mentioned HPV may not be involeved in the overall pathogenesis of primary squamous cell carcinoma of the endometrium. Thus, our present case should be the first report of ESCC with HPV infection, and this case suggests that HPV may be involved in the overall pathogenesis of primary ESCC.

\section{References}

Czerwenka K, Lu Y, Heuss F, Manavi M, and Kubista E. Human papillomavirus detection of endometrioid carcinoma with squamous differentiation of the uterine corpus. Gynecol Oncol 1996;61:210-214.

Fluhmann DF. Squamous epithelium in the endometrium in benign and malignant conditions. Surg Gynecol Obstet 1928; 46:309-316.

Goodman A, Zukerberg LR, Rice LW, Fuller AF, Young RH et al. Squamous cell carcinoma of the endometrioum: A report of eight cases and a review of the literature. Gynecol Oncol 1996; 61:54-60.

Im DD, Shah KV, and Rosenshein NB. Report of three new cases of squamous carcinoma of the endometrium with emphasis in the HPV status. Gynecol Oncol 1995; 56:464-469.

Yamamoto $\mathrm{Y}$, Izumi K, Otsuka $\mathrm{H}$, Kishi $\mathrm{Y}$, Mimura $\mathrm{T}$ et al. Primary squamous cell carcinoma of the endometrium: A case report and a suggestion of new histogenesis. Int $\mathbf{J}$ Gynecol Pathol 1995; 14:75-80.

Yoshikawa H, Kawana T, Kitagawa K, Mizuno $\mathrm{M}$, Yoshikura $\mathrm{H}$ et al. Detection and typing of multiple genital human papillomaviruses by DNA amplification with consensus primer. Jpn J Cancer Res 1991; 82:524-531.

zur Hausen H, and de Villers EM. Human papillomaviruses. Annu Rev Microbiol 1994; 48:427-447. 